\title{
Receiver functions of CCDSN and crustal structure of Chinese mainland*
}

\author{
Xuzhang Shen ${ }^{1, *}$ and Huilan Zhou ${ }^{2}$ \\ ${ }^{1}$ Lanzhou Institute of Seismology, China Earthquake Administration, Lanzhou 730000, China \\ ${ }^{2}$ Laboratory of Computational Geodynamics, Graduate University of Chinese Academy of \\ Sciences, Beijing 100049, China
}

\begin{abstract}
The teleseismic receiver functions of 48 stations belonging to the CCDSN are used to invert the crustal structure beneath each station with the neighborhood algorithm. Thin layers with low velocity have been found beneath eight stations with "abnormal" observed receiver functions. Unreasonable results of few stations have been adjusted lightly with the trial-and-error method. The final result indicates that the crust in the western China is relatively thicker than the eastern China. The crust thickness beneath the Tibetan plateau is very large, which reaches $84 \mathrm{~km}$ at the station LSA. Double-crust structure exists below the stations LSA and CAD in Tibet, which might imply the collision between the Indian and Eurasian plates. A pronounced low velocity zone in the lower crust beneath the station TNC of Yunnan province might relate to the high temperature or emergence of partially molten material caused by Quaternary volcano, magma and geothermal activities in this area. The Moho is a transitional zone made up of thin layers instead of simple sharp discontinuity beneath several stations. The Conrad discontinuity is clearly identified beneath 20 stations mainly in the southeastern China, whereas it is blurry beneath 14 stations and uncertain beneath remaining stations.
\end{abstract}

Key words: receiver function; neighborhood algorithm; Chinese mainland; crust structure CLC number: P315.3 Document code: A

\section{Introduction}

China is located in the southeastern part of the Eurasian continent, which is bounded by the subducting Pacific and Philippine plates to the east and the converging Indian plate to the southwest. The interactions of all of those plates lead to the complex crust and upper mantle structure in China, thus providing an ideal place to study the ongoing continental dynamics.

Different seismic methods have been applied to study crust and upper-mantle structure and topography of the Moho discontinuity in Chinese mainland, such as seismic reflection and refraction of active seismic source (Zhang et al., 1996; Li et al., 2001), teleseismic receiver functions (Langston, 1979; Liu et al.,

\footnotetext{
* Received 1 October 2011; accepted in revised form 12 December 2011; published 10 February 2012.

† Corresponding author. e-mail: shenxzh@gmail.com

(C) The Seismological Society of China, Institute of Geophysics, China Earthquake Administration, and Springer-Verlag Berlin Heidelberg 2012
}

1997; Yang and Zhou, 2001; Vinnika et al., 2004; Zheng et al., 2005; Ma and Zhou, 2007; Chen et al., 2010), body wave tomography (Huang et al., 2001; Pei et al., 2004) and surface wave dispersion inversion (Huang et al., 2003).

The receiver function (Langston, 1979) is an effective tool to study the velocity structure of crust and upper mantle, especially for discontinuities. Deconvolution in the frequency domain (Clayton and Wiggins, 1976) is widely used to calculate the observed receiver functions. Liu et al. (1996) developed a maximum likelihood estimation of the complex spectrum ratio of receiver function. Park and Levin (2000) developed a multiple-taper spectral correlation algorithm. Deconvolution technique in the time domain was presented by Gurrola et al. (1995), and the multiple iterative technique provided by Ligorria and Ammon (1999) has been generally used to calculate receiver functions, and $\mathrm{Wu}$ et al. (2003) selected Wiener filter in deconvolution in order to ensure the stability of the receiver functions. Unlike the frequency domain, the water level, a factor 
with somewhat arbitrary, is not needed in the time domain, so the deconvolved results in the time domain are more stable.

The inversion of velocity structure using receiver function has been developed for linear and nonlinear cases. Dependency on initial model is avoided in nonlinear inversion, so it has become popular recently. Liu et al. (1997) used a complex spectrum ratio of receiver functions to invert the structure beneath 10 stations of China Digital Seismograph Network (CDSN) down to the depth of $100 \mathrm{~km}$. Shibutani et al. (1996) used a genetic algorithm to study the crust and upper mantle structure under eastern Australia. Sambridge (1999a, b) proposed a neighborhood algorithm and applied it to the receiver function inversion. Clitheroe et al. (2000) also applied this method to study the sediment and upper-crust structure in Australia. Zhou and Yang (2003) proposed a peeling genetic algorithm and extended the inversion depth to $700 \mathrm{~km}$. Zheng et al. (2005) used an adapted hybrid global waveform inversion to study the sediment structure beneath the Bohai basin.

In recent decade, abundant data have been accumulated with the development of seismic observational technology and the tremendous increase of the number of seismograph stations, which makes it possible to get higher resolution crustal structure. In this paper, teleseismic waveforms recorded by China Center of Digital Seismic Network (CCDSN) have been used to calculate radial observed receiver functions (ORFs), and then to invert the velocity structure beneath each station with the neighborhood algorithm (NA). Previous researches (Ma and Zhou, 2007; Chen et al., 2010) mainly focused on the depth of Moho in this region; while we will investigate the detailed velocity structure including the variation of shear velocity $\left(v_{\mathrm{S}}\right)$ with depth $(h)$, the buried depths of the Moho $\left(h_{\mathrm{M}}\right)$ and the Conrad discontinuity $\left(h_{\mathrm{C}}\right)$, and the crustal and upper mantle velocity structure in some complicated regions where the Indian plate collides with the Eurasian plate. In addition, the abnormal structure corresponding to the low velocity shallow crust are also explored.

\section{Data and ORF}

The CCDSN consists of 48 stations, which are well-proportioned distributed; the average distance between two nearest stations is 500-600 km (Figure 1). Three types of broadband seismic sensors are equipped at these stations. The first type is STS-2 seismometer, which are equipped at 10 stations (BJI, KMI, LSA, MDJ, QZN, SSE, WMQ, XAN, ENS and HLR). The second, JCZ-1 seismometer, is flat to velocity from frequency $0.0033 \mathrm{~Hz}$ to $20 \mathrm{~Hz}$ with the sensitivity of $10^{3} \mathrm{v} \cdot \mathrm{m}^{-1} \cdot \mathrm{s}^{-1}$ (Cai et al., 1995). It is equipped at 10 stations (CD2, GTA, GOM, GZH, HTA, HEH, HHC, SNY, TIA and WHN). The last type, CTS-1 seismometer, which is flat to velocity from frequency $0.0083 \mathrm{~Hz}$ to $20 \mathrm{~Hz}$, with the sensitivity $2 \times 10^{3} \mathrm{v} \cdot \mathrm{m}^{-1} \cdot \mathrm{s}^{-1}$ (Cai et al., 2004), is equipped at the remaining 28 stations (CN2, DL2, GYA, NJ2, QZH, TIY, AXX, BNX, CAD, CNS, GUL, HEF, HNS, HTG, KSH, LYN, NAQ, NNC, PZH, SZN, TNC, WZH, WUS, XLT, XSA, YCH, LZH and $\mathrm{SQH}$ ).

We collected records of teleseismic events $\left(M_{\mathrm{S}}>\right.$ $5.5)$ with epicentral distances in the range of $30^{\circ}-90^{\circ}$ during 2001 to 2003 at first, among which the waveforms with high signal to noise ratio (SNR) and good quality were selected. The ORFs were calculated with the iterative deconvolution method in the time domain, and a low-pass Gaussian filter with the half-width constant $\alpha=4$ was applied (Ligorria and Ammon, 1999). For each station, the ORFs for events with different azimuths are very similar except $\mathrm{YCH}$ and NAQ. It shows that the structure of different directions beneath one station is nearly same, so the structure can be simulated with a horizontal layering model. Structure beneath the stations YCH and NAQ will be studied later.

The ORF is often contaminated by the scattering of seismic waves and other noises, which affect the correctness of inversion results and then need to be suppressed. In order to increase the data's SNR, we selected the events gathered around the New Britain region which is to the southeast of China (Figure 1). The travel paths of the waveforms from these events to one station are almost same and the arrival times of the pronounced peak on ORF are well correlated. The noise can be suppressed by stacking. The stacking results (also denoted with ORF) were used to invert the crustal structure beneath each station.

Figure 2 shows the 24 ORFs of the LZH station and the stacking result. The peak values at the time segment from direct $\mathrm{P}$ to 20 seconds later are synchronized and have been strengthened after stacking. The ORFs of other stations are treated similarly to LZH. Number of earthquakes used for stacking at each station is listed in Table 1.

The maximum of the synthetic receiver function (TRF) is often synchronous with the direct $\mathrm{P}$ for the simple crust model, such as IASP91, and most of the 
ORFs in this paper are also like this, but the maxima of ORFs for the eight stations (HHC, CD2, KSH, TNC,

$\mathrm{XSA}, \mathrm{HEF}, \mathrm{LZH}$, and WUS) are delayed to the direct
$\mathrm{P}$ (Figure 3). This 'abnormity' shows the structure beneath these stations have special characteristics, so we discussed them individually.

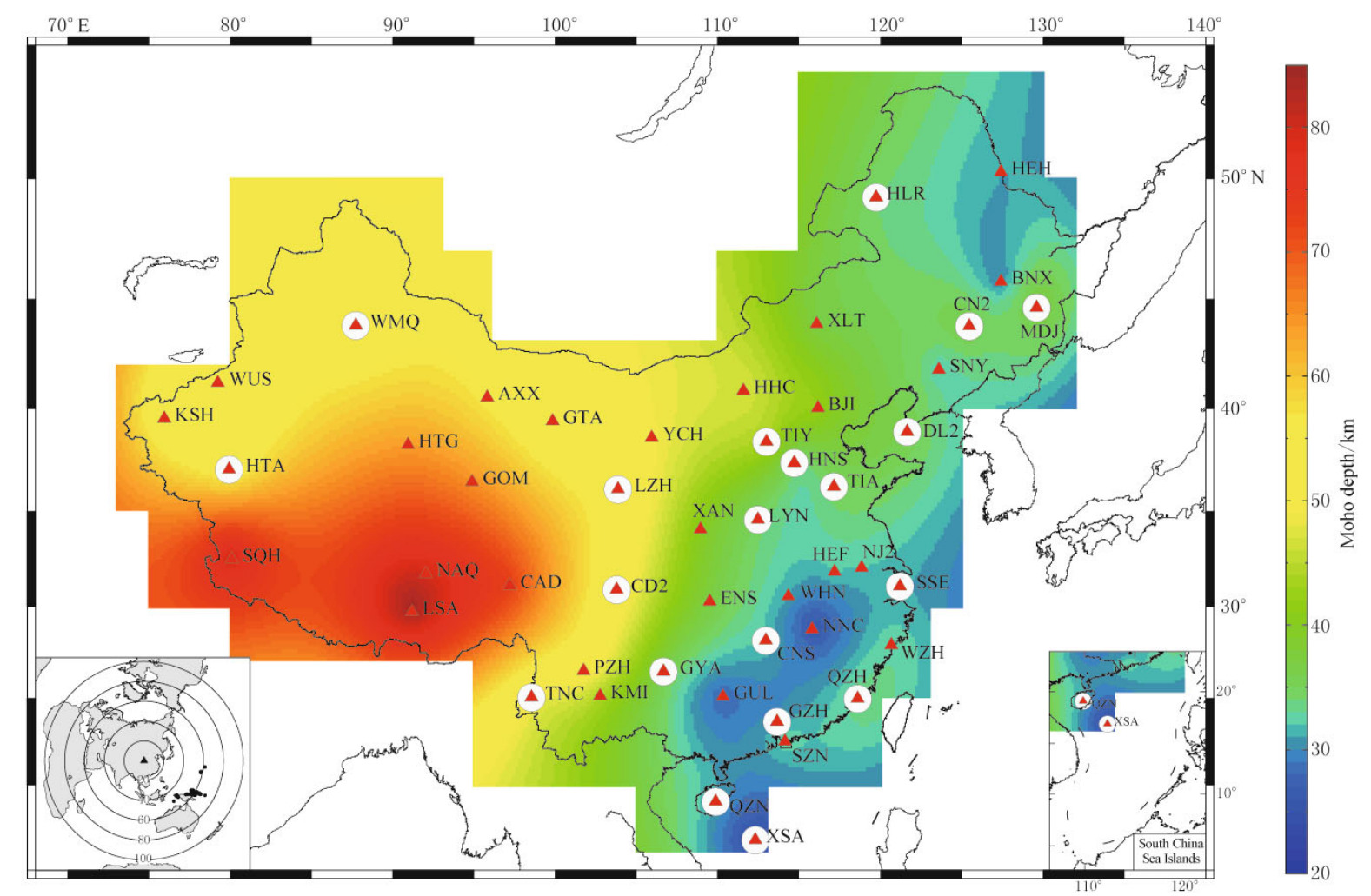

Figure 1 Moho depth distribution in Chinese mainland. Triangles stand for stations, and the white circle indicates that the Conrad discontinuity beneath the station is clear. Inset is the map of the events used in the study. The black triangles stand for the center of the CCDSN. The black dots represent the earthquakes. The circle indicates the same epicentral distance and the number shows the value of the distance in degree.

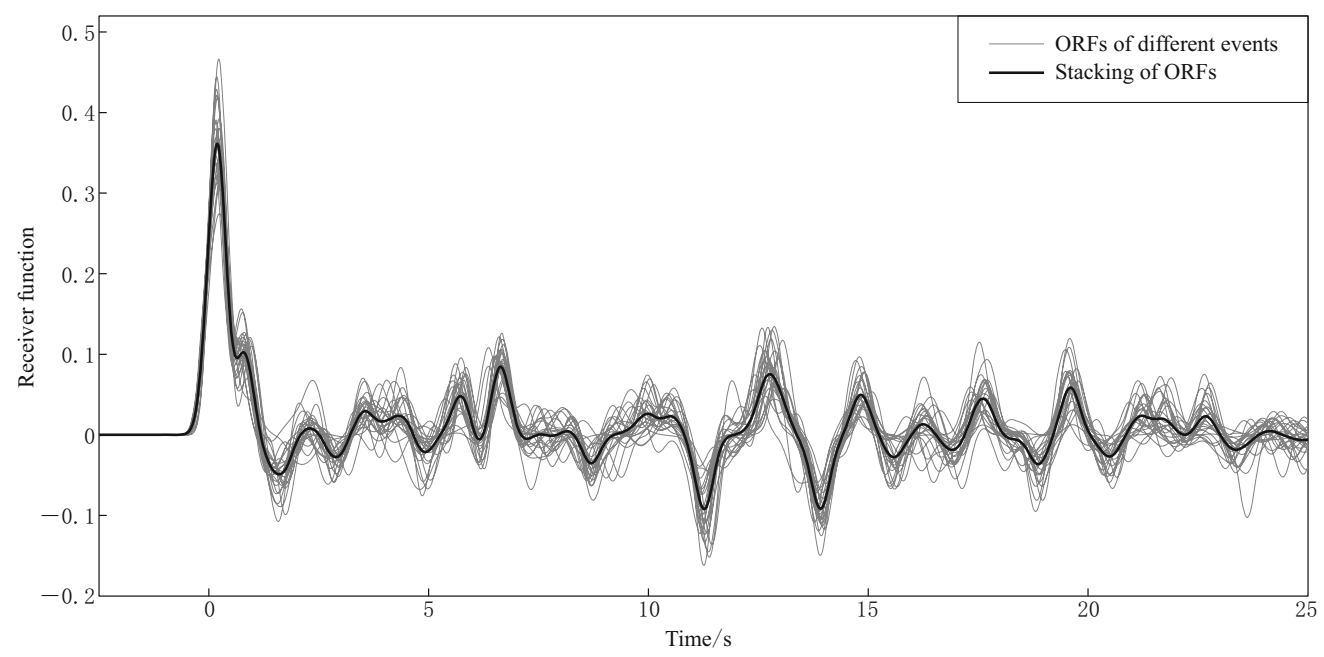

Figure 2 The 24 selected ORFs of the station LZH and their stacking results. 
Table 1 Inversion results of the Moho depth $h_{\mathrm{M}}$ and Conrad discontinuity depth $h_{\mathrm{C}}$

\begin{tabular}{cccc||cccc||cccc}
\hline Station & $\begin{array}{c}\text { Number of } \\
\text { events }\end{array}$ & $\begin{array}{c}h_{\mathrm{M}} \\
/ \mathrm{km}\end{array}$ & $\begin{array}{c}h_{\mathrm{C}} \\
/ \mathrm{km}\end{array}$ & Station & $\begin{array}{c}\text { Number of } \\
\text { events }\end{array}$ & $\begin{array}{c}h_{\mathrm{M}} \\
/ \mathrm{km}\end{array}$ & $\begin{array}{c}h_{\mathrm{C}} \\
/ \mathrm{km}\end{array}$ & Station & $\begin{array}{c}\text { Number of } \\
\text { events }\end{array}$ & $\begin{array}{c}h_{\mathrm{M}} \\
/ \mathrm{km}\end{array}$ & $\begin{array}{c}h_{\mathrm{C}} \\
/ \mathrm{km}\end{array}$ \\
\hline MDJ & 17 & 38 & 14 & QZH & 21 & 34 & 15 & GTA & 29 & 52 & - \\
BNX & 20 & 30 & - & SZN & 22 & 33 & $?$ & AXX & 29 & 56 & - \\
CN2 & 27 & 37 & 27 & QZN & 20 & 31 & 10 & PZH & 20 & 52 & $?$ \\
SNY & 14 & 32 & - & XSA & 5 & 25 & 15 & KMI & 22 & 44 & $?$ \\
DL2 & 8 & 36 & 27 & GZH & 30 & 30 & 13 & TNC & 26 & 49 & 17 \\
HLR & 6 & 34 & 10 & WHN & 21 & 31 & - & LSA & 22 & 84 & double \\
HEH & 24 & 31 & - & NNC & 19 & 26 & - & GOM & 17 & 65 & - \\
TIA & 20 & 35 & 9 & CNS & 21 & 32 & 9 & HTG & 2 & 64 & - \\
BJI & 30 & 42 & - & ENS & 25 & 37 & $?$ & CAD & 8 & 73 & double \\
XLT & 31 & 37 & - & GUL & 21 & 28 & - & SQH & 13 & 80 & $?$ \\
HHC & 32 & 47 & - & HEF & 13 & 32 & $?$ & WMQ & 22 & 53 & 21 \\
HNS & 29 & 33 & 9 & NJ2 & 9 & 32 & - & WUS & 25 & 52 & - \\
TIY & 25 & 44 & 11 & CD2 & 27 & 52 & 15 & KSH & 16 & 52 & $?$ \\
LYN & 18 & 34 & 16 & XAN & 19 & 35 & $?$ & HTA & 23 & 54 & 12 \\
SSE & 15 & 31 & 9 & GYA & 25 & 36 & 19 & & & \\
WZH & 21 & 37 & $?$ & LZH & 24 & 54 & 29 & & & \\
\hline
\end{tabular}

Note: "- " means the Conrad discontinuity is blurry. "?" represents that it can not be determined. 'Double' represents that there maybe double Conrad discontinuities.

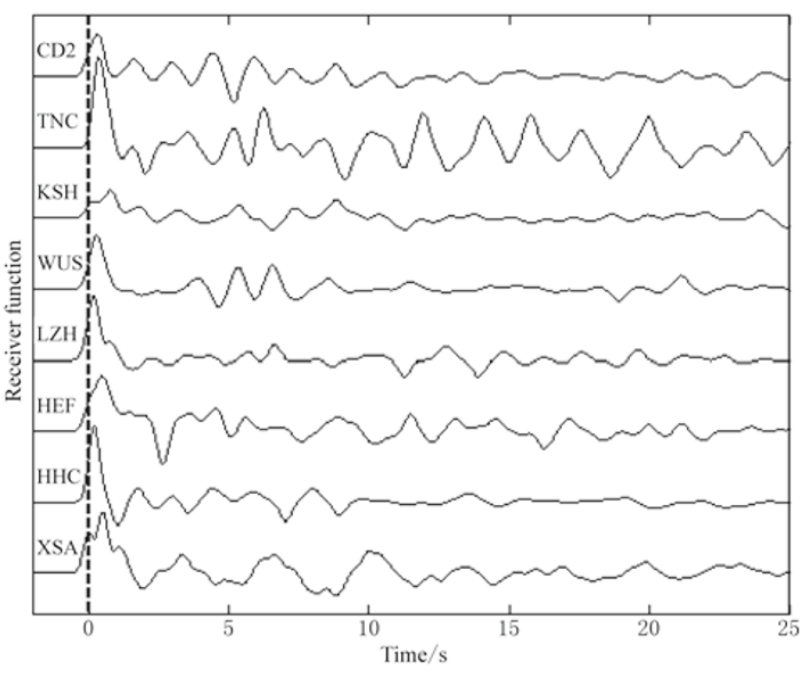

Figure 3 Abnormal ORFs of eight stations. Letters on the left indicate the station names, and broken line shows the arrival of $\mathrm{P}$ wave.

\section{Inversion method and numerical test}

\subsection{Introduction of NA inversion}

The neighborhood algorithm (NA) (Sambridge, 1999a) was used to search for the optimum solution during inversion. Based on some simple principles, this method divides the undetermined parameter space into small parts with Voronoi cell, and generates complicated searching process by adjusting only two parameters.
The $N$ th iteration can fully utilize all the information provided by the $(N-1)$ th iteration during the searching process and the final result can avoid falling into local minimum. So it has the advantage of searching for the optimum solution in the highest dimension space. We improved the parameterization to make inversion model match with forward model (Shen and Zhou, 2004). The reflexivity method (Kennett, 1983) is used to calculate the synthetic response of the medium.

\subsection{Choice of inversion parameters}

Two schemes of the inversion parameters were tested with synthetic receiver function of the IASP91 model. In scheme I, the crust is divided into eight layers, and the undetermined parameters are thickness $\left(h_{i}\right)$, shear velocity $\left(v_{\mathrm{S}_{i}}\right)$ and $R_{i}\left(v_{\mathrm{P}_{i}} / v_{\mathrm{S}_{i}}\right)$ for the $i$ th layer. In scheme II, the crust is also divided into eight layers, but only the $h_{i}$ and the $v_{\mathrm{S}_{i}}$ are inverted, the value of $R_{i}$ is given based on the IASP91 model in advance. Other constants are all same in two kinds of schemes. The quality factors, $Q_{v_{\mathrm{P}}}$ and $Q_{v_{\mathrm{S}}}$, are 50 and 25 respectively above the Moho and 100 and 25 beneath the Moho. The density of the each layer $\left(\rho_{i}\right)$ is assumed to follow the Birth equation.

Figure 4 is the inversion result of numerical tests of two schemes. The optimums of the $h_{i}$ and $v_{\mathrm{S}_{i}}$ of the two schemes are both close to the values from the IASP91 model after 750 iterations. However, the values of the $R_{i}$ have a large departure from that of the IASP91 model in the scheme I, so we select the scheme II to process the observed data. Namely, the crust is 
divided into eight layers for the most of stations and the searching ranges of inversion parameters are listed in Table 2. For several stations with more complicated structure, number of layers and parameter ranges can be adjusted on the base of this method. The average model of the last 10 iterations is considered as the final inversion result. The results of the last 10 iterations are much close in the numerical tests and in the inversion with the observe data. So we think the final model is the most possible one. The batches of solutions on the sense of statistics are not discussed in detail.
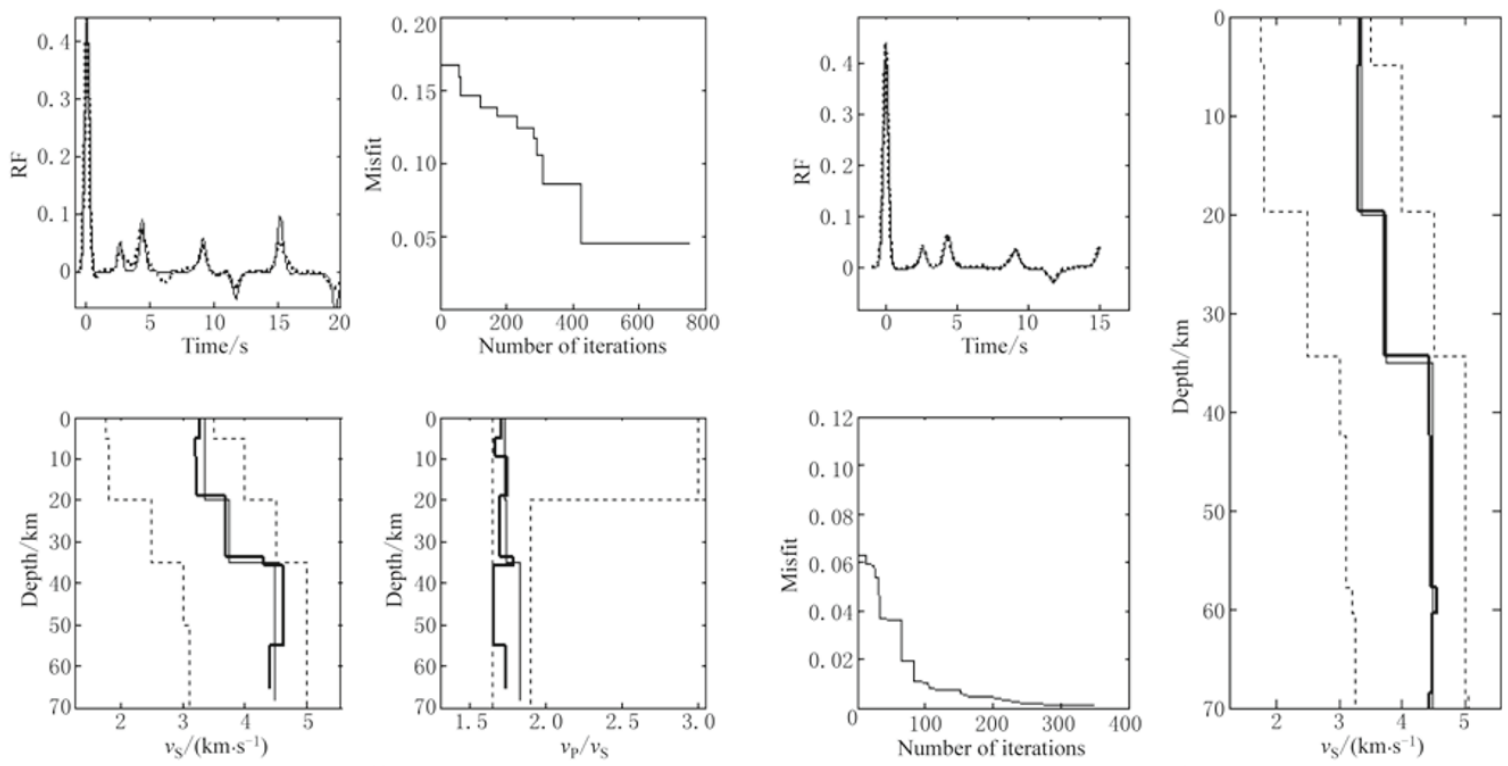

(a)

(b)

Figure 4 Comparison of inversion parameters in the schemes I (a) and II (b). (a) Numerical test result of scheme I. Upper left panel: Comparison of ORF (solid line) and synthetic receiver function for the final inversion model (dotted line). Upper right panel: Change in misfit during inversion. Lower left panel: Searching boundary of $v_{\mathrm{S}}$ and inversion result. Thick solid line denotes velocity result, thin solid line denotes $v_{\mathrm{S}}$ from the IASP91 model, broken line denotes searching range of $v_{\mathrm{S}}$. Lower right panel: Searching boundary of $v_{\mathrm{P}} / v_{\mathrm{S}}$ and inversion result. Thick solid line is result of $v_{\mathrm{P}} / v_{\mathrm{S}}$, thin solid line is $v_{\mathrm{P}} / v_{\mathrm{S}}$ of the IASP91 model, broken line is searching range of $v_{\mathrm{P}} / v_{\mathrm{S}}$. (b) Numerical test result of scheme II. Upper left panel: Same as upper left of (a). Lower left: Same as upper right of (a). Right panel: Same as lower left of (a).

Table 2 Searching range of inverted parameters

\begin{tabular}{ccccc}
\hline Layer & $\begin{array}{c}h_{\min } \\
/ \mathrm{km}\end{array}$ & $\begin{array}{c}h_{\max } \\
/ \mathrm{km}\end{array}$ & $\begin{array}{c}v_{\mathrm{S}_{\min }} \\
/\left(\mathrm{km} \cdot \mathrm{s}^{-1}\right)\end{array}$ & $\begin{array}{c}v_{\mathrm{S}_{\max }} \\
/\left(\mathrm{km} \cdot \mathrm{s}^{-1}\right)\end{array}$ \\
\hline 1 & 0.50 & 5.00 & 2.00 & 3.50 \\
2 & 1.50 & 15.00 & 3.00 & 4.20 \\
3 & 1.50 & 15.00 & 3.20 & 4.80 \\
4 & 1.50 & 15.00 & 3.20 & 5.00 \\
5 & 2.00 & 20.00 & 3.60 & 5.00 \\
6 & 2.00 & 20.00 & 4.00 & 5.00 \\
7 & 2.00 & 20.00 & 4.00 & 5.00 \\
8 & 3.00 & 20.00 & 4.10 & 5.00 \\
\hline
\end{tabular}

\subsection{Numerical simulation of 'abnormal' receiv- er functions}

According to Ammon (1991) about the effect of velocity structure on the amplitude of receiver function, when only the first-order P-to-S phase is considered, the radial receiver function $r(t)$ can be expressed as

$$
r(t)=\frac{r_{0}}{z_{0}}\left[\delta(t)+A_{\mathrm{Ps}} \delta\left(t-t_{\mathrm{Ps}}\right)\right]
$$

and

$$
\frac{r_{0}}{z_{0}}=\frac{2 p v_{\mathrm{S}} \sqrt{1-p^{2} v_{\mathrm{S}}^{2}}}{1-2 p^{2} v_{\mathrm{S}}^{2}},
$$

where $r_{0}$ and $z_{0}$ are the amplitude of $\mathrm{P}$ wave in radial and vertical directions, $A_{\mathrm{Ps}}$ is the refraction coefficient of P-to-S conversion on the bottom of the first layer, $t_{\mathrm{Ps}}$ is the arrive time of $\mathrm{P}$-to- $\mathrm{S}$ conversion phase, $p$ is the ray parameter, and $v_{\mathrm{S}}$ is the shear velocity of the first layer. This formula shows that the maximum of amplitude ratio $r_{0} / z_{0}$ of $r(t)$, if $t_{\mathrm{Ps}}$ is large enough, is basically synchronous with the direct $\mathrm{P}$ wave. When a thin layer exists beneath the surface with low velocity, $t_{\mathrm{Ps}}$ becomes small. It also leads to a short interval between the $\mathrm{Ps}$ and $\mathrm{P}$, so the $\mathrm{Ps}$ rides on the $\mathrm{P}$, and the 
maximum value of $r(t)$ is delayed and then results in such 'abnormality'.

We constructed the crust models with one or two low velocity layers covering on the IASP91 model, and calculated their TRFs. Considering the property of the clay and the sedimentation, for the first layer $R_{i}=2.5$, $\rho=1.3 \mathrm{~g} / \mathrm{cm}^{3}, Q_{v_{\mathrm{P}}}=20$ and $Q_{v_{\mathrm{S}}}=10$; for the second layer $R_{i}=2.0, \rho=2.0 \mathrm{~g} / \mathrm{cm}^{3}, Q_{v_{\mathrm{P}}}=30$ and $Q_{v_{\mathrm{S}}}=15$, all TRFs are displayed in Figure 5 .

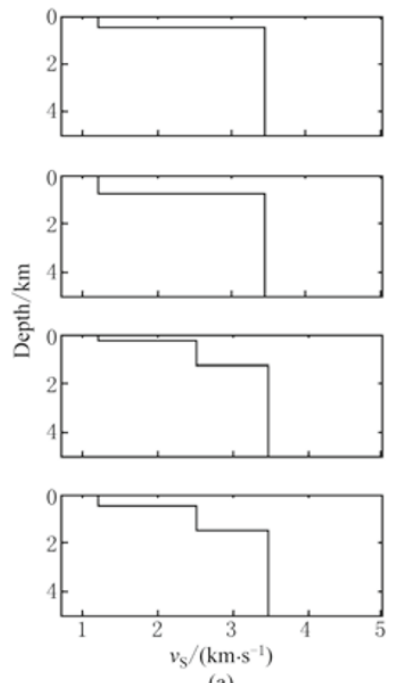

(a)

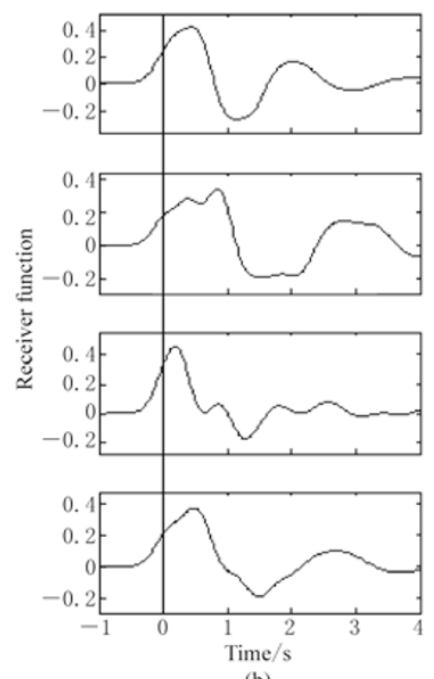

(b)
Figure 5 Influence of low velocity layer near the surface on the receiver functions. (a) Velocity model; (b) Synthetic receiver function, and arrival time of direct $\mathrm{P}$ equals zero.

The numerical tests show that the maximum of the TRF is delayed to the direct $\mathrm{P}$ when one or two low velocity layers are near the surface, which leads to a peak before the maximum. Since the result can explain the 'abnormal' ORFs of eight stations, we deduce that the low velocity layers may exist beneath those eight stations. The first layer in Table 2 is divided into two layers when the 'abnormal' ORF are used to inversion. The searching ranges of parameters for the 1st layer are thickness $h=0-1 \mathrm{~km}, v_{\mathrm{S}}=0.5-3.0 \mathrm{~km} / \mathrm{s}$; while $h=2-5 \mathrm{~km}, v_{\mathrm{S}}=1.5-3.0 \mathrm{~km} / \mathrm{s}$ for the 2 nd layer.

\section{Data processing and inversion results}

The velocity structure below the 46 stations have been inverted with the above-mentioned method. At the same time, the buried depths of the Moho and the Conrad discontinuity (if it exists) have been determined with all results listed in Table 1 . In order to present the inversion result in a convenient way, we divide the whole region into three parts such as eastern region, Xinjiang region, and Tibet and its adjacent region.

Based on the IASP91 model and the prior research results, we have selected three criteria to determine the Moho discontinuity. (1) The jumping value of $v_{\mathrm{S}}\left(\Delta v_{\mathrm{S}}\right)$ is larger than $0.3 \mathrm{~km} / \mathrm{s}$. (2) $v_{\mathrm{S}}$ under the Moho is larger than $4.2 \mathrm{~km} / \mathrm{s}$. (3) Moho depth $h_{\mathrm{M}}$ is in the range of $20-55 \mathrm{~km}$ in the eastern region, $30-70 \mathrm{~km}$ in the Xinjiang region and $30-90 \mathrm{~km}$ in the Tibet and its adjacent region. If there is no discontinuity satisfying the three criteria simultaneously, the waveform of the ORFs, especially the $\mathrm{P}_{\mathrm{MS}}$, will be used to determine the depth of the Moho. If there are one or more strong discontinuities no more than $5 \mathrm{~km}$ upon the Moho, the Moho will be considered as a transitional zone made up of several thin layers, and marked with M-zone.

The Conrad discontinuity is the boundary of the upper and lower crusts, but not a global discontinuity. Its buried depth drastically varies in different region. The criteria of the Conrad discontinuity refer to the IASP91 model. If there is only one pronounced discontinuity between $9 \mathrm{~km}$ and $0.7 h_{\mathrm{M}}$ in depth, $\Delta v_{\mathrm{S}}$ is about $0.3 \mathrm{~km} / \mathrm{s}$, and $v_{\mathrm{S}}$ under discontinuity is about $3.8 \mathrm{~km} / \mathrm{s}$, the Conrad discontinuity under the station is clearly defined. The Conrad discontinuity cannot be identified if there are multi-discontinuities in this range (marked with $D_{1}, D_{2}$ and $D_{3}$, etc.). The Conrad discontinuity is not clear if there are no evident discontinuities in the range.

\subsection{Eastern region}

The 31 stations (MDJ, BNX, HEH, CN2, SNY, DL2, HLR, XLT, BJI, HNS, TIA, HHC, LYN, TIY, SSE, WZH, QZH, SZN, QZN, XSA, GZH, WHN, NNC, CNS, ENS, GUL, HEF, NJ2, CD2, GYA and XAN) are in the eastern region. Figure 6 gives the inversion result$\mathrm{s}$ for all the stations in this region. It shows the range of parameters and the change in the misfit during the inversion, the optimum model and its TRF.

The Moho depths $h_{\mathrm{M}}$ beneath the most stations have been determined accurately in this region, in addition, a special method was applied to judge the Moho in the stations HLR, WZH, SZN and XAN. Although the discontinuity at the depth of $51 \mathrm{~km}$ fits the criteria of the Moho, we still consider $h_{\mathrm{M}}=34 \mathrm{~km}$ beneath the station HLR because the strongest pulse of the ORF and TRF appears 5 seconds after the direct $P$. We think that this pulse should be $\mathrm{P}_{\mathrm{MS}}$ and it is related to 34 $\mathrm{km}$ discontinuity. The stations WZH, SZN and XAN are the same as HLR. In the range of criterion (3), only one 

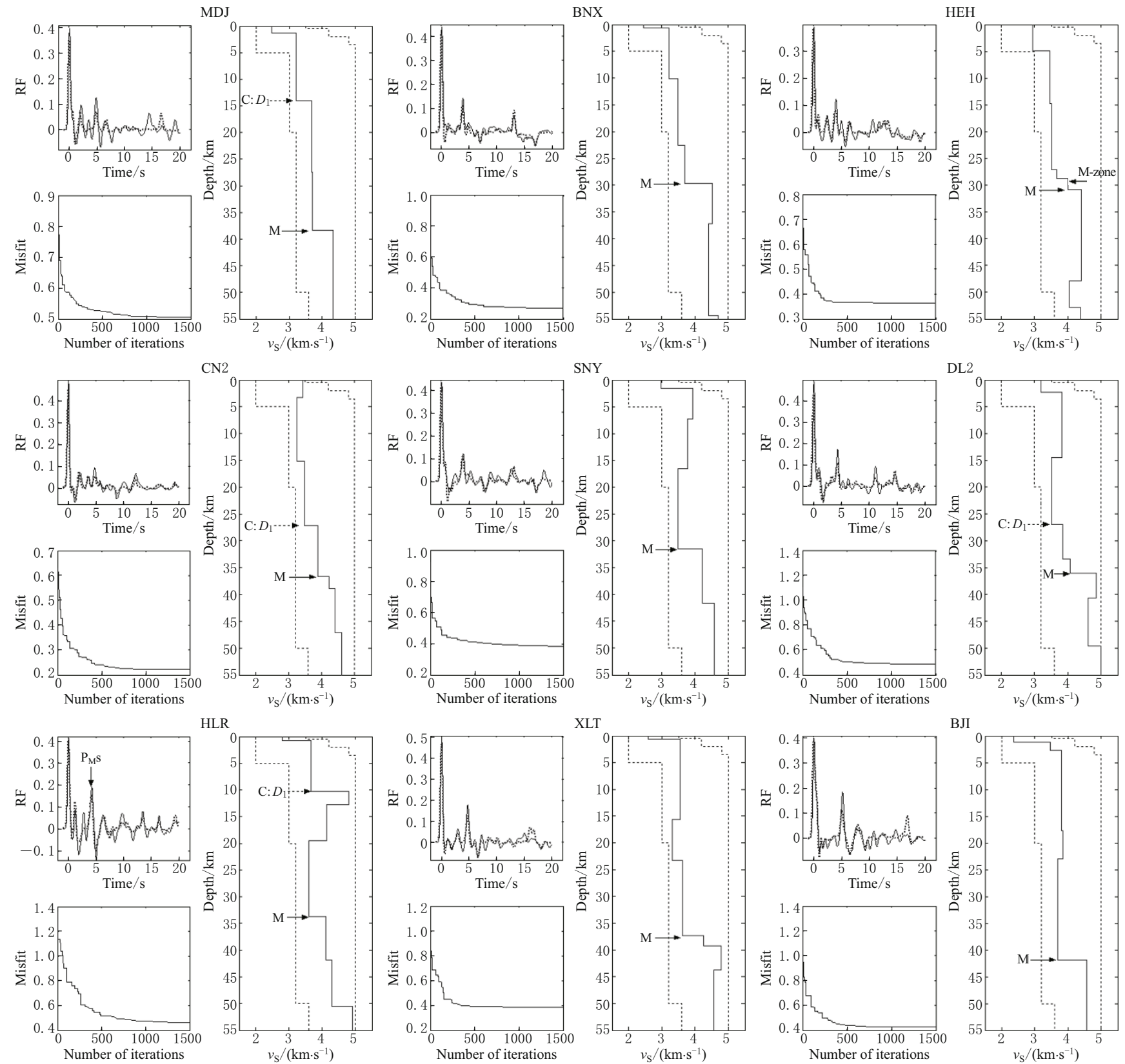

HNS
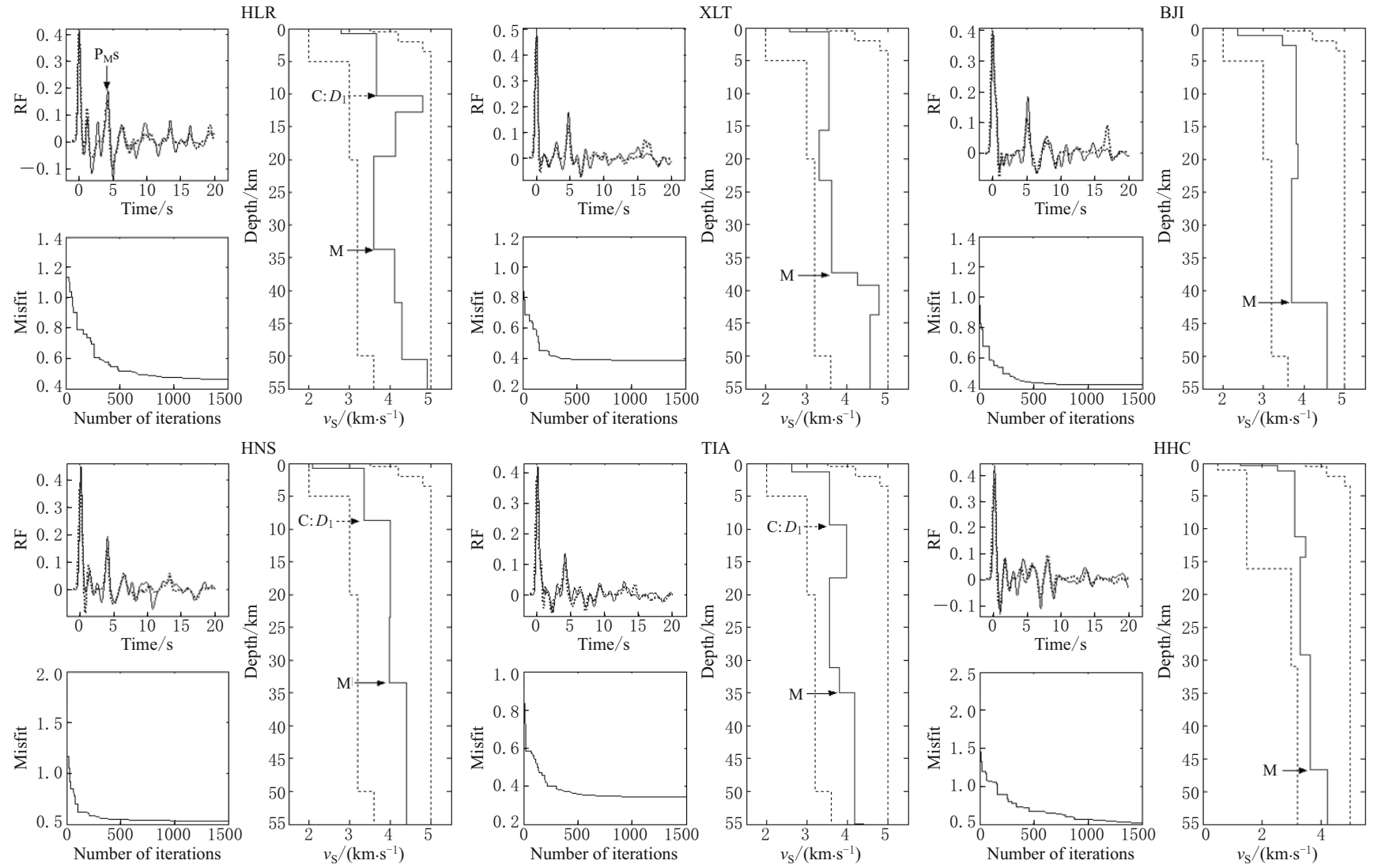

Figure 6 Inversion results for the 31 stations in the eastern region (Same as Figure 4b). 'M' indicates the location of the Moho, 'C' indicates the location of the Conrad discontinuity, and $D_{1}$ and $D_{2}$ are multi-discontinuities. 

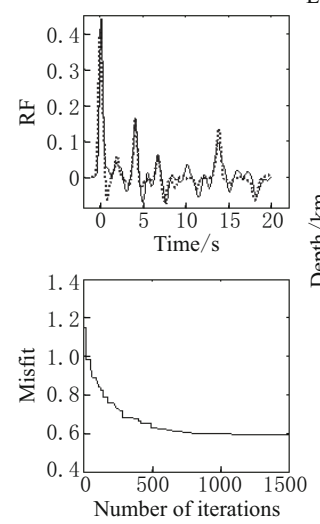

YN

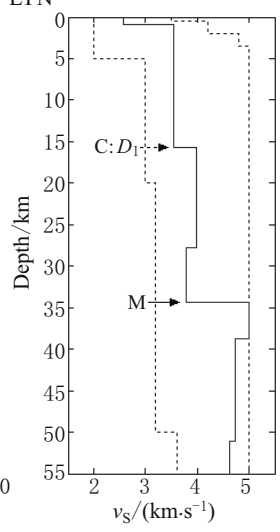

WZH
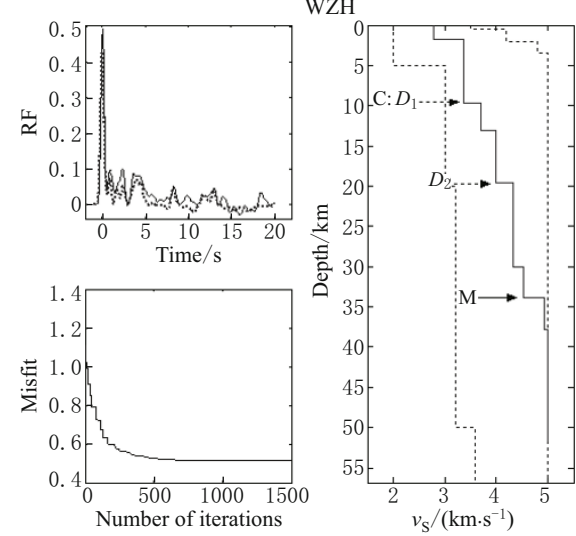

QZN
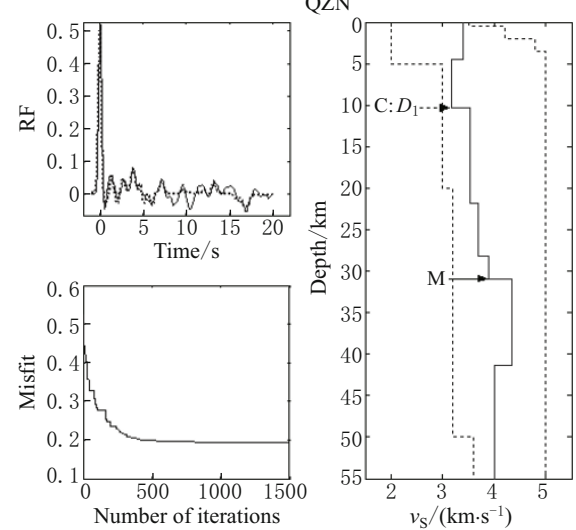

WHN
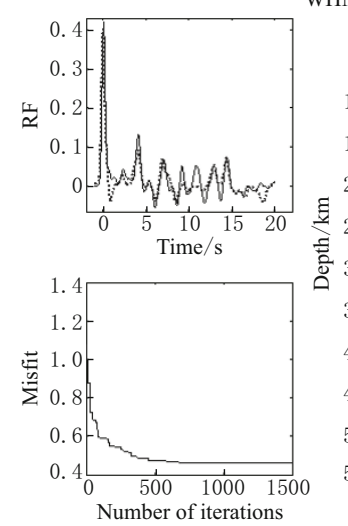
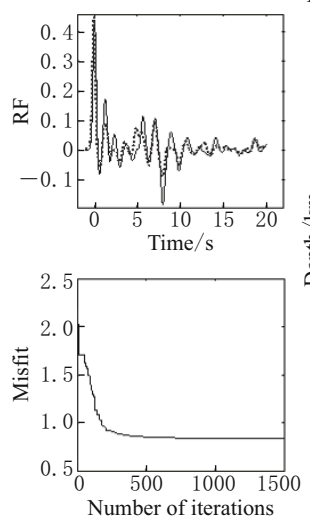

TIY
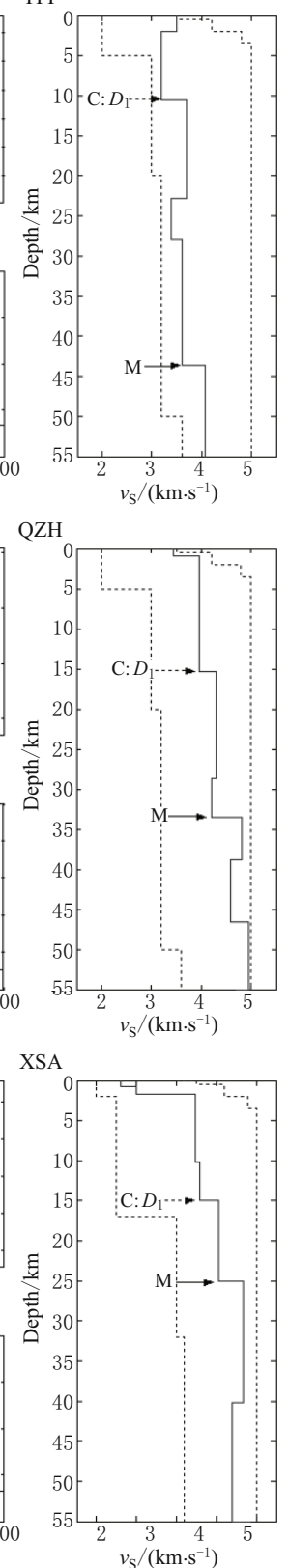

$\mathrm{NNC}$
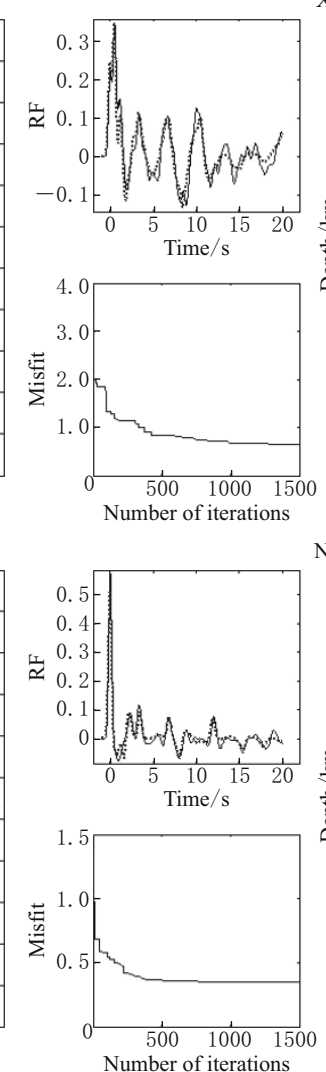

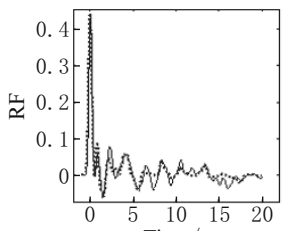

SSE
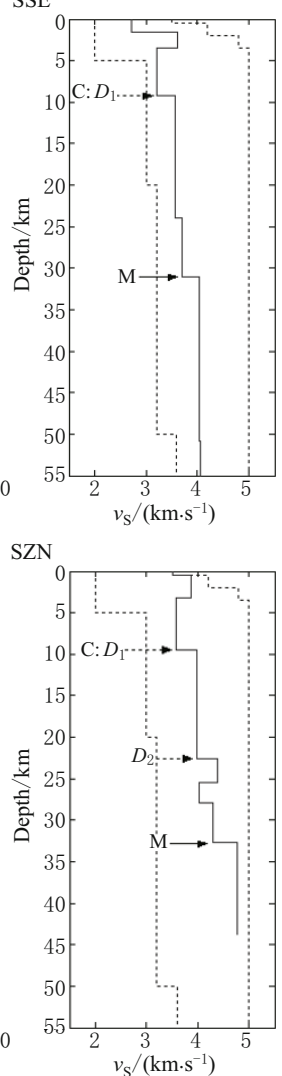

GZH
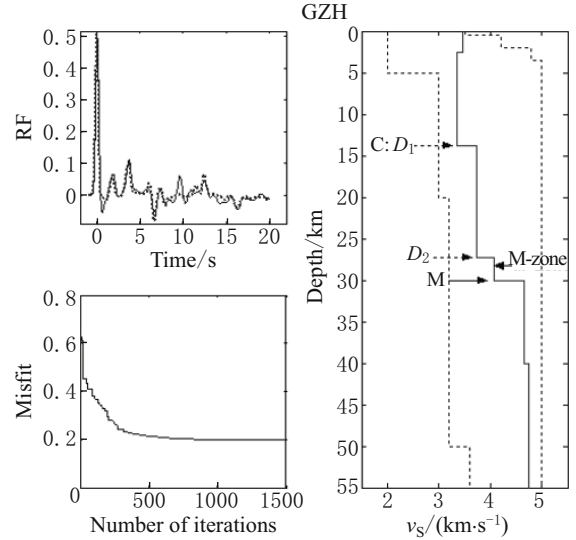

CNS
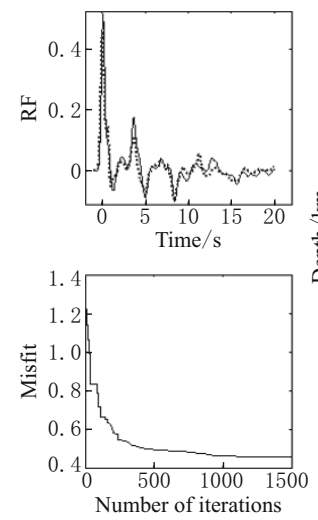

Figure 6 Inversion results for the 31 stations in the eastern region (Same as Figure 4b). 'M' indicates the location of the Moho, ' $\mathrm{C}$ ' indicates the location of the Conrad discontinuity, and $D_{1}$ and $D_{2}$ are multi-discontinuities. 

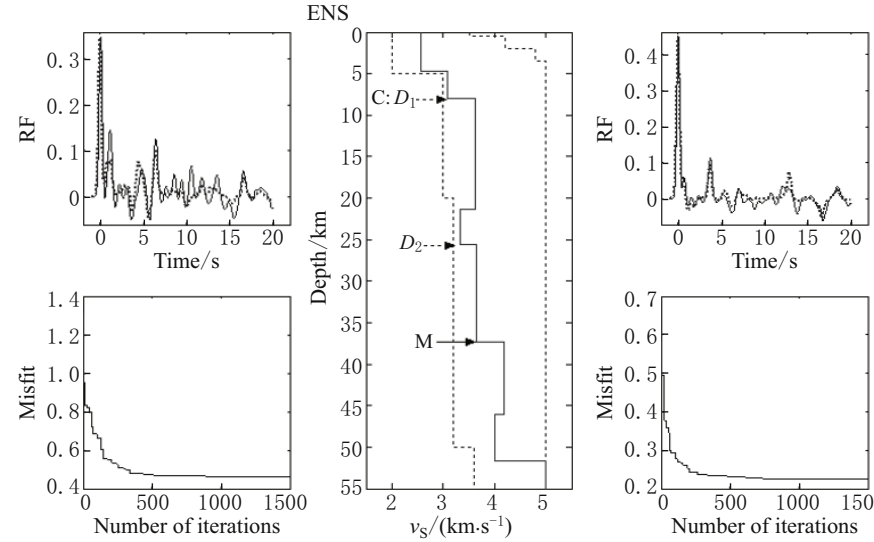

GUL
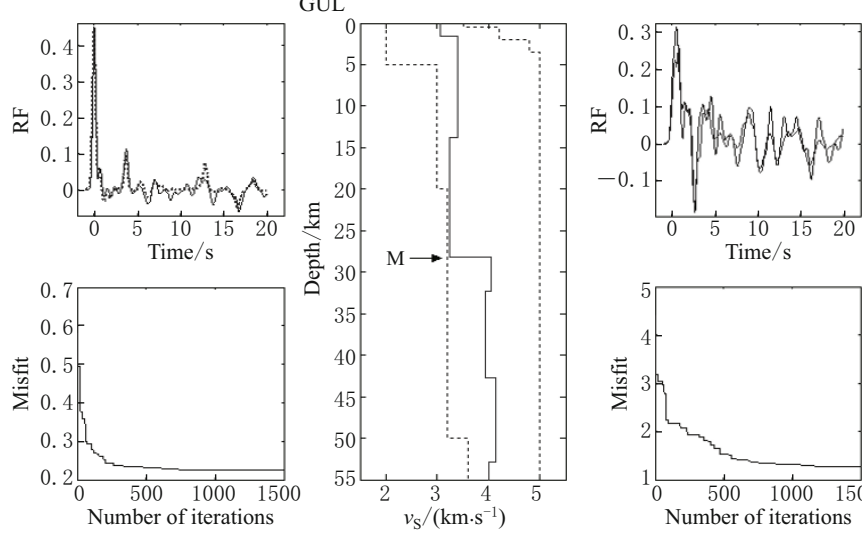

HEF
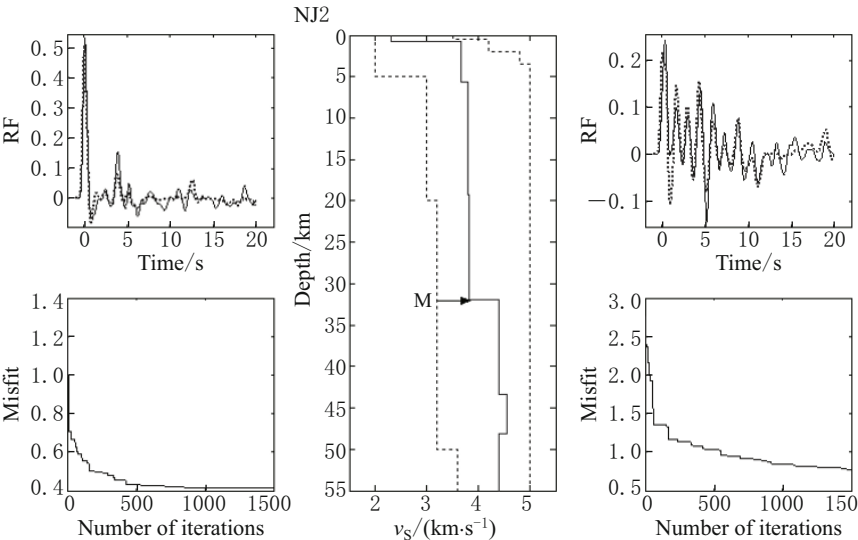

$\mathrm{CD} 2$
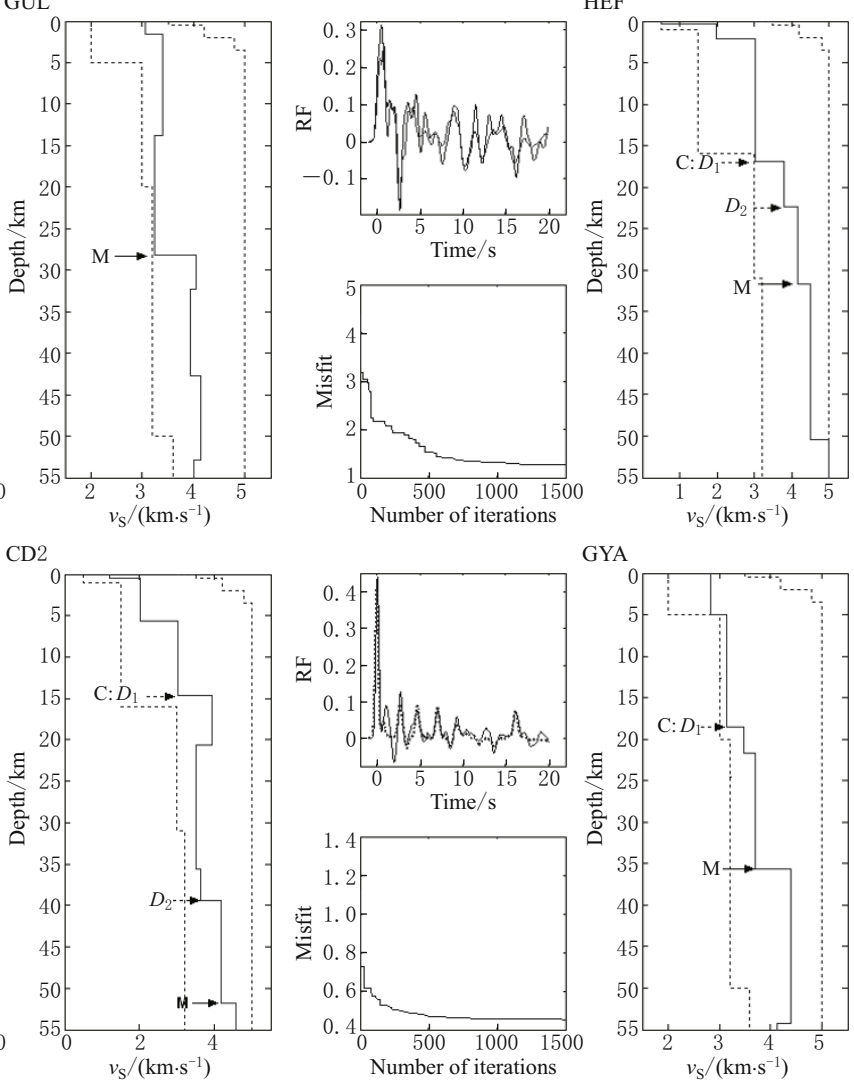

GYA
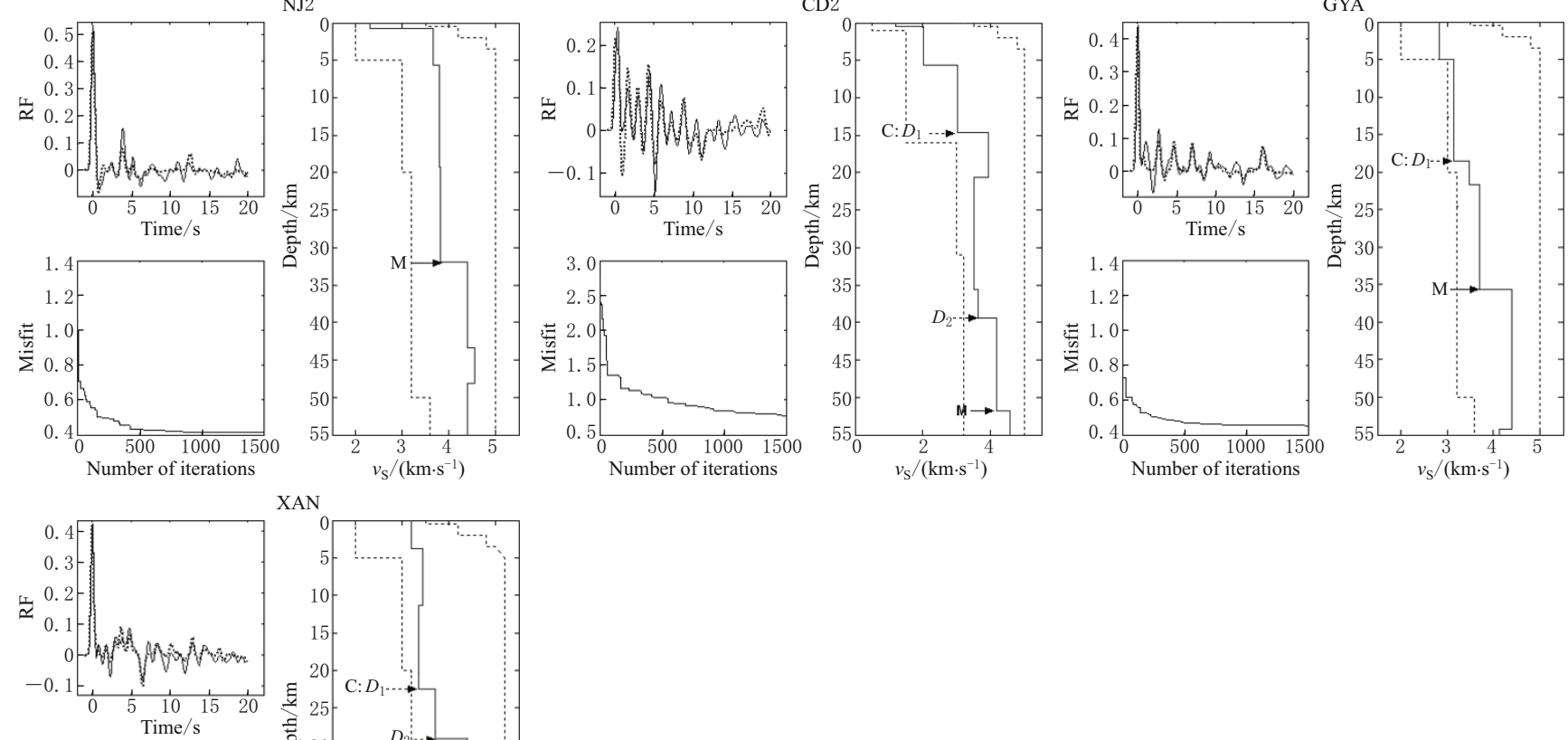

XAN
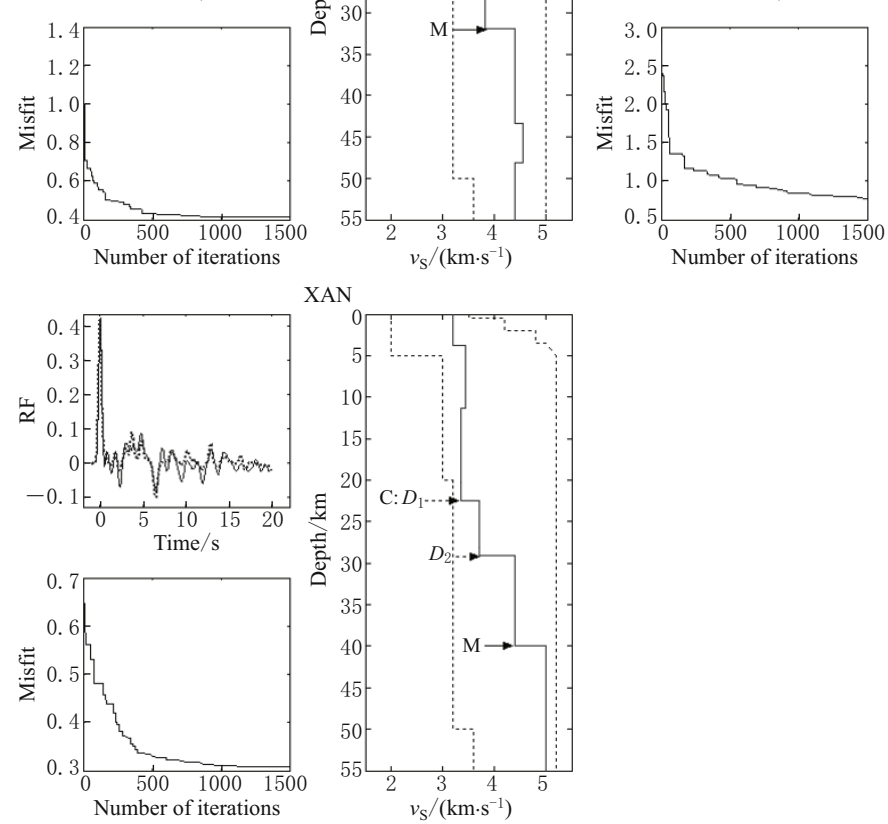

$v_{\mathrm{S}}\left(\mathrm{km} \cdot \mathrm{s}^{-1}\right)$

Figure 6 Inversion results for the 31 stations in the eastern region (Same as Figure 4b). 'M' indicates the location of the Moho, ' $\mathrm{C}$ ' indicates the location of the Conrad discontinuity, and $D_{1}$ and $D_{2}$ are multi-discontinuities.

distinguished discontinuity exits beneath the stations SSE and GUL. Although it does not satisfy the Moho criterion fully, we still consider it the Moho. In addition, there are M-zones beneath the stations HEH, GZH and WHN.

Based on above-mentioned criteria, the Conrad discontinuities beneath the stations MDJ, CN2, DL2, HLR, TIA, HNS, TIY, LYN, SSE, QZH, QZN, XSA, GZH, CNS, CD2 and GYA are clearly defined, and the depths of Conrad discontinuity have also been estimated (Table 1). However the Conrad discontinuities can not be judged beneath the stations WZH, SZN, ENS, $\mathrm{HEF}$ and XAN, and are blurry beneath other stations.

\subsection{Xinjiang region}

The stations HTA, WMQ, KSH and WSH are located in the edge of the Tarim basin in the Xinjiang region. Ma (1989) reported that, in this region, the thickest sediment of Chinese mainland exists. Inversion results (Figure 7) show that the values of $h_{\mathrm{M}}$ change from $52 \mathrm{~km}$ to $54 \mathrm{~km}$. The depth of low velocity layers beneath the stations HTA and KSH are $6 \mathrm{~km}$ and 11 $\mathrm{km}$, respectively, and their characteristics are similar to 

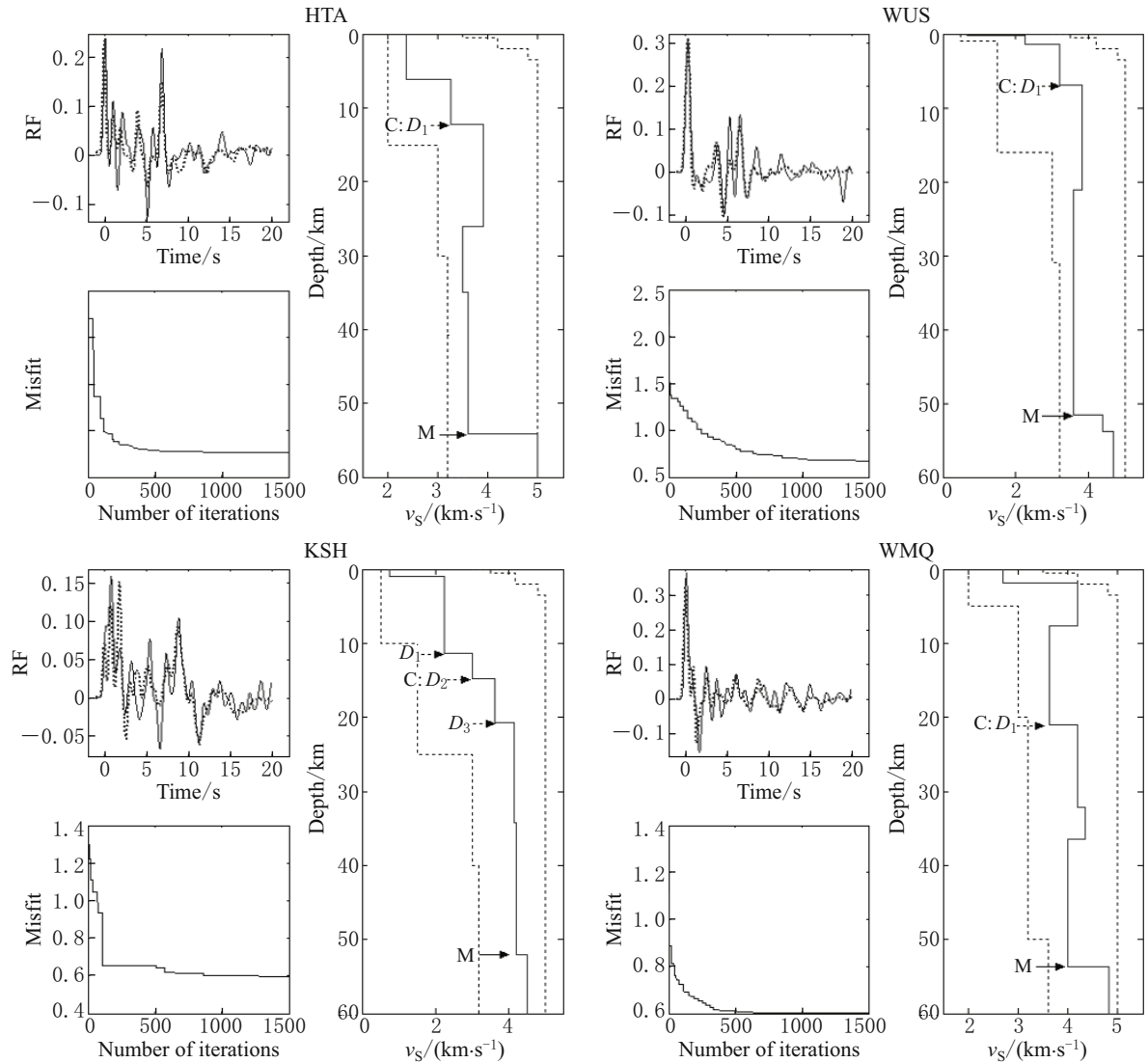

Figure 7 Inversion results of the four stations in the Xinjiang region (Same as Figure 6).

sedimentation, which is consistent with the previous researches (Ma, 1989).

The Conrad discontinuities beneath WMQ and HTA are clear, but illegible beneath WUS. The discontinuity cannot be determined under KSH due to complex crust.

\subsection{Tibet and its adjacent region}

There are eleven stations in Tibet and its adjacent region, including LZH, GTA, AXX, PZH, KMI, TNC, LSA, GOM, HTG, CAD and SQH. Figure 8 shows that the crustal structure of this region are very complicated, and the values of $h_{\mathrm{M}}$ also vary in broad range.

Since the crust of Tibetan plateau is most complicated and thickest in the world, we divided the crust into ten layers beneath the stations LSA, SQH, CAD, HTG and GOM in the Tibetan plateau. Inversion results also indicate such complexity.

The $h_{\mathrm{M}}$ values of LSA, CAD, GOM, THG and $\mathrm{SQH}$ are larger than other stations. Beneath the station LSA, the $h_{\mathrm{M}}$ reaches to $84 \mathrm{~km}$. The $h_{\mathrm{M}}$ also reaches to $80 \mathrm{~km}$ beneath the station $\mathrm{SQH}$, which is also located in Tibet. The pulse, which appears 10 seconds after the direct $\mathrm{P}$ on $\mathrm{ORF}$ of the LSA station, should be the $\mathrm{P}_{\mathrm{MS}}$ referred to the previous studies (Ma, 1989; Zhu et al., 1993; Kind et al., 1996). However, the multiple reverberations $\mathrm{P}_{\mathrm{M} 1} \mathrm{pP}_{\mathrm{M} 1} \mathrm{~S}$ from $24 \mathrm{~km}$ discontinuity (Figure $8, \mathrm{M}_{1}$ in LSA result) appears 10 seconds after the direct $\mathrm{P}$, which disturbs the judgement of the Moho. In order to make the result more reasonable, we adopted trial-and-error method to verify the inversion result of LSA station lightly. Higher and lower velocity layers exist alternately among crust under the stations CAD and LSA, which may imply the double crust structure beneath the Tibetan plateau originated from the Indian plate diving down to the Eurasian plate.

Because the stations TNC, PZH and KMI are located in the southeastern edge of the Tibet, crustal structure are thus complicated; range of the $h_{\mathrm{M}}$ in this region is $44-51 \mathrm{~km}$. There are two visible discontinuities in the crust beneath the station KMI. High and low velocity layers overlap together under the station PZH. Low velocity zone exists in the lower crust under the station TNC, while the high velocity zones in the middle crust. The Myanmar, Indian and Yangtze plates meet together in this region, so it is reasonable that the crust is complicated. 
Figure 8 Inversion results of the eleven stations in Tibet and its adjacent region (Same as Figure 6). 
In the northeastern margin of the Tibetan plateau, crustal structure beneath stations LZH, GTA and AXX are simpler; the $h_{\mathrm{M}}$ in this region ranges $52-56 \mathrm{~km}$, and there is M-zone beneath the station GTA.

The Conrad discontinuities beneath stations LZH and TNC are clear, while they are blurry beneath the stations GTA, AXX, GOM and HTG. There may be two Conrad discontinuities beneath the stations LSA and CAD, whereas Conrad discontinuities beneath other stations are very difficult to estimate.

\subsection{Lower velocity layer beneath eight stations with "abnormal" ORF}

The inversion results of the upper two layers with broad searching range beneath eight stations (mentioned in section 3.3) with "abnormal" ORF are listed in Table 3.

Table 3 Inversion results of two shallow layers under eight stations with "abnormal" ORFs

\begin{tabular}{|c|c|c|c|c|}
\hline \multirow[b]{2}{*}{ Station } & \multicolumn{2}{|c|}{ 1st layer } & \multicolumn{2}{|c|}{ 2nd layer } \\
\hline & $\begin{array}{c}h \\
/ \mathrm{km}\end{array}$ & $\begin{array}{c}v_{\mathrm{S}} \\
/\left(\mathrm{km} \cdot \mathrm{s}^{-1}\right)\end{array}$ & $\begin{array}{c}h \\
/ \mathrm{km}\end{array}$ & $\begin{array}{c}v_{\mathrm{S}} \\
/\left(\mathrm{km} \cdot \mathrm{s}^{-1}\right)\end{array}$ \\
\hline $\mathrm{HHC}$ & 0.37 & 1.29 & 0.81 & 2.53 \\
\hline CD2 & 0.49 & 1.19 & 5.16 & 2.02 \\
\hline $\mathrm{HEF}$ & 0.28 & 0.50 & 1.82 & 1.99 \\
\hline XSA & 0.69 & 1.61 & 0.97 & 2.00 \\
\hline TNC & 0.23 & 0.50 & 1.73 & 2.20 \\
\hline $\mathrm{LZH}$ & 0.99 & 2.01 & 0.65 & 2.95 \\
\hline WUS & 0.24 & 0.68 & 1.11 & 2.26 \\
\hline $\mathrm{KSH}$ & 0.97 & 0.75 & 10.42 & 2.24 \\
\hline
\end{tabular}

Shear velocity of the first layer beneath the station LZH is about $2 \mathrm{~km} / \mathrm{s}$, and that of other stations are from 0.5 to $1.6 \mathrm{~km} / \mathrm{s}$. It shows that there is thin layer of loose media beneath these stations. Characteristic of the second layer is more similar to the sedimentation.

\section{Discussion and conclusions}

The Moho topography of Chinese mainland (Figure 1) was obtained from the $h_{\mathrm{M}}$ values of 46 stations (Table 1). We can get the following conclusions based on the Moho topography and velocity structure as shown in Figures 5, 6 and 7.

1) Crust is thicker in the western China, while it is thinner in the eastern. Especially the thickest crust exists in the Tibetan plateau, and the thinnest crust in the southeastern China. The depths of Moho beneath several stations are different from the previous results (Ma and Zhou, 2007; Chen et al., 2010). For the station $\mathrm{CN} 2, h_{\mathrm{M}}$ equals to $29.3 \mathrm{~km}$ in Chen et al. (2010) and $28.6 \mathrm{~km}$ in Ma and Zhou (2007), respectively. Our result indicates that there is a discontinuity about $26 \mathrm{~km}$, but the $37 \mathrm{~km}$ is a more reasonable value according to our criterion and the Moho depth of the adjacent stations. For the stations WZH and NNC, the ORF is complicated, which means the crustal model can not be simplified as a single crust model used in the $h-k$ stacking method. The signals from shallow structure might interfere the determination of the signals from Moho. We inverted the detailed velocity structure and also considered the shallow structure to fit all pulses on the ORF, so our results might be acceptable. The $h_{\mathrm{M}}$ beneath PZH equals to $52 \mathrm{~km}$ in our results, while it is $42.9 \mathrm{~km}$ in Chen et al. (2010) and $52.2 \mathrm{~km}$ in Ma and Zhou (2007), respectively. As mentioned above, the ORF of this station is also complicated, if only the simple crustal model is considered, the difference might be given with the $h$ - $k$ stacking method, so the inversion method is a better choice to determine the Moho depth for the complicated ORFs.

2) The largest thickness of the Tibet reaches 84 $\mathrm{km}$ beneath the station LSA. Double crustal structure is defined below the stations LSA and CAD, which evidences collision of the Indian and Eurasian plates. Kind et al. (1996) inferred there is a strong low velocity zone under the Lhasa block, and explained it with partially molten crustal layer. While this low velocity zone may be explained by the Indian plate's subducting beneath the Eurasia plate at present.

3) An obvious low velocity zone exists in the lower crust beneath the station TNC. Tomography of this region (Huang et al., 2001) also shows such low velocity. In this region, the Quaternary volcanoes, geothermal activities and crustal earthquakes are common, so the low velocity might be related to the soft lower crust or partially molten material due to high temperature magma.

4) Numerical tests show that the shallower velocity structure have important influence on the maximum amplitude and its arrival time on receiver functions. The maximum value of ORFs may be delayed if there are thin layers with low velocity near the surface. The ORFs of the eight stations exhibit such "abnormality", and inversion results also show the existence of thin layers with low velocity near the surface. The station CD2 locates in the Sichuan basin; WUS and KSH are on the inside edge of the Tarim basin; HEF, HHC and XSA are in the Hefei basin, river basin, and Xisha fault basin, respectively. LZH is located in the region with thick loess, and TNC is on the Myanmar-Tengchong fold with complicate tectonic setting. All of them have the condition to form the low velocity layer in shallow crust. 
5) The Conrad discontinuities are clearly defined beneath 20 stations (Figure 1), most of which are gathered together in the southeastern China; while they are blurry under 14 stations and undetermined beneath other stations. There may be two Conrad discontinuities beneath the stations LSA and CAD with double crustal structure. Data about the Conrad discontinuities in the whole study region is scarce, so the results about the Conrad discontinuities in this paper still need to be further refined by seismic phases in the future.

6 ) The stations of the CCDSN are still sparsely distributed in Chinese mainland, especially in the western area, so the transverse variance of the crustal structure is not well defined. Results must be improved in the future with increase of stations and release of more data of the regional seismic network.

Acknowledgements The anonymous reviewers reviewed the paper carefully and provided many detailed suggestions. Dr. Macon Sambridge of ANU supplied the program codes of NA method, Dr. Zhongxian Huang from China Earthquake Administration kindly provided data, Dr. Yanlu Ma and Dr. Meijian AN gave help about debugging the program. The authors sincerely appreciate all of them. This research was supported by the basic research and development fund from Institute of Earthquake Science, China Earthquake Administration (grant No. 2011IESLZ05) and the National Natural Science Foundation of China (grant Nos. 40374009 and 40904014).

\section{References}

Ammon C J (1991). The isolation of receiver effects from teleseismic P waveforms. Bull Seismol Soc Am 81: 2 5042510.

Cai Y, Lü Y, Zhou Y and Chen J (2004). CTS-1 very broadband seismometer. Journal of Geodesy and Geodynamics 24(3): 109-114 (in Chinese with English abstract).

Cai Y, Lü Y, Zhou Y, Chen J, Shao Z and Wang H (1995). JCZ-1 ultra broadband seismometer. Crustal Deformation and Earthquake 15(3): 1-8 (in Chinese with English abstract).

Clayton R W and Wiggins R A (1976). Source shape estimation and deconvolution of teleseismic body wave. Geophys J $R$ astr Soc 47: 105-117.

Chen Y, Niu F, Liu R, Huang Z, Tkalčić H, Sun L and Chan W (2010). Crustal structure beneath China from receiver function analysis. J Geophys Res 115: B03307, doi:10.1029/2009JB006386.

Clitheroe G, Gudmundsson O and Kennett B L N (2000). Sedimentary and upper crustal structure of Australia from receiver functions. Australian Journal of Earth Sci- ences 47: 209-216.

Gurrola H, Baker F G and Minster J B (1995). Simultaneous time-domain deconvolution with application to the computer of receiver functions. Geophys J Int 120: 537-543.

Huang J, Zheng S and Zhao D (2001). The seismic tomography in Sichuan and Yunnan. Chinese J Geophys 44(Suppl.): 127-135 (in Chinese with English abstract).

Huang Z, Su W, Peng Y, Zheng Y and Li H (2003). Rayleigh wave tomography of China and adjacent regions. $J$ Geophys Res 108(B2): 2073, doi:10.1029/2001JB001696.

Kennett B L N (1983). Seismic Wave Propagation in Stratified Media. Cambridge University Press, Cambridge, UK, $285 p$ p.

Kennett B L N and Engdahl E R (1991). Travel times for global earthquake location and phase identification. Geophys J Int 105: 429-465.

Kind R, Ni J, Zhao W, Wu J, Yuan X, Zhao L, Sandvol E, Reese C, Nabelek J and Hearn T (1996). Evidence from earthquake data for a partially molten crustal layer in southern Tibet. Science 274: 1 692-1 694.

Langston C A (1979). Structure under Mount Rainier, Washington, inferred from teleseismic body waves. $J$ Geophys Res 84(B4): 4 749-4 762.

Li S, Zhang X, Song Z, Shi J, Deng H, Yang J, Zhang C and Ren Q (2001). Three-dimensional crustal structure of the capital area obtained by adjoint inversion of DSS data from multiple profiles. Chinese J Geophys 44(3): 360-368 (in Chinese with English abstract).

Ligorria J P and Ammon C J (1999). Iterative deconvolution and receiver-function estimation. Bull Seismol Soc Am 89: 1 395-1 400.

Liu Q, Kind R and Li S (1996). Maximal likelihood estimation and nonlinear inversion of the complex receiver function spectrum ratio. Chinese J Geophys 39(4): 500511 (in Chinese with English abstract).

Liu Q, Kind R and Li S (1997). The receiver function at the stations of the Chinese digital seismic network (CDSN) and their nonlinear inversion. Chinese J Geophys 40(3): 356-367 (in Chinese with English abstract).

Ma X (1989). Lithospheric Dynamics Atlas of China. China Cartographic Publishing House, Beijing, 68 (in Chinese).

Ma Y and Zhou H (2007). Crustal thicknesses and Poisson's ratios in China by joint analysis of teleseismic receiver functions and Rayleigh wave dispersion. Geophys Res Lett 34: L12304, doi:10.1029/2007GL029848.

Park J and Levin V (2000). Receiver functions from multiple-taper spectral correlation estimates. Bull Seismol Soc Am 90: 1 507-1 520.

Pei S, Xu Z and Wang S (2004). Sn wave tomography in the uppermost mantle beneath the China continent and adjacent regions. Chinese J Geophys 47(2): 250-256 (in Chinese with English abstract).

Sambridge M (1999a). Geophysical inversion with a neighbourhood algorithm - I. searching a parameter space. 
Geophys J Int 138: 479-494.

Sambridge M (1999b). Geophysical inversion with a neighbourhood algorithm - II. appraising the ensemble. Geophys J Int 138: 727-746.

Shen X and Zhou H (2004). Improvement on inversion method of neighborhood algorithm with receiver functions and research of crust structure under station HLR. Journal of the Graduate School of the Chinese Academy of Sciences 22(3): 320-328 (in Chinese with English abstract).

Shibutani T, Sambridge M and Kennett B L N (1996). Genetic algorithm inversion for receiver functions with application to crust and uppermost mantle structure beneath Eastern Australia. Geophys Res Lett 23(14): $1829-1832$.

Vinnika L, Reigberb C, Aleshina I, Kosareva G, Kabanb M, Oreshina S and Roecker S (2004). Receiver function tomography of the central Tien Shan. Earth Planet Sci Lett 22: 131-146.

Wu Q, Tian X, Zhang N, Li W and Zeng R (2003). Receiver function estimated by Wiener filtering. Earthquake Re- search in China 19(1): 41-47 (in Chinese with English abstract).

Yang Y and Zhou H (2001). Application of receiver function method to estimate the buried depths of discontinuities in the upper mantle beneath China and adjacent area. Chinese J Geophys 44(6): 781-792 (in Chinese with English abstract).

Zhang X, Wang C and Liu Y (1996). Fine crustal structure in Yanqing-Huailai region by deep seismic reflection profiling. Chinese J Geophys 39(3): 356-364.

Zheng T, Zhao L and Chen L (2005). A detailed receiver function image of the sedimentary structure in the Bohai Bay Basin. Phys Earth Planet Inter 152: 129-143.

Zhou H and Yang Y (2003). Peeling genetic algorithm of receiver functions inversion for upper mantle structure and discontinuities. Chinese J Geophys 46(3): 546-556 (in Chinese with English abstract).

Zhu L, Zeng R, Wu F, Owens T and Randall G (1993). Preliminary study of crust-upper mantle structure of the Tibetan Plateau by using broadband teleseismic body waveforms. Acta Seismologica Sinica 6: 305-316. 